\title{
Analysis on the Interactive Cultivation Model between Master and Graduate
}

\author{
Junting Li \\ School of economics and management \\ Xi'an Shiyou University \\ Shaanxi, China \\ jtinglee@163.com
}

\author{
Pengfei Jiao* \\ School of economics and management \\ Xi'an Shiyou University \\ Shaanxi, China \\ 1149427022@qq.com
}

\begin{abstract}
Tutorial system is adopted to educate the graduates. The relationship between the graduate students and their tutors is the key factor to influence the education for all-around development of the graduate students. The paper proposed four perspectives in the graduate students and teacher interaction cultivation which are training institutions and training system; teaching effectiveness; beneficial guidance; fusion guidance in order to further shorten the tutors and graduate students in space and time between the thinking mode and target mode. The data was collected through questionnaires, and quantitative analysis, besides it pointed out that the foundation and core element is teaching effectiveness in the graduate education function, and putted forward relevant suggestions.
\end{abstract}

Keywords—graduate; supervisor; cultivation model; interaction

\section{PROBLEMS RAISED}

In the course of postgraduate training, the tutor conduct academic and research guidance to graduate students, provide academic and other resources support. The graduates are engaged in course study and subject research under the guidance of the instructor and the two sides form a pair of interactive relations. For graduates, teacher-student relationship is the most important interpersonal relationship and even the future academic path has a crucial impact ${ }^{[1]}$. Therefore, the mentor and students interaction model for the cultivation of graduates can't be ignored. The interaction mentioned in this article refers to the cultivating mode, the teacher and students interact on a model to enhance the ability of the students, including school hardware and software factors to influence students' ability, mining from multiple angles.

\section{RESEARCH METHODS AND IDEAS}

The existing educational mechanism of graduate education is lagging behind, and the training mode between instructors and students is lagging behind. In order to solve these problems, we first need to clarify key factors to solve the problem. In order to overcome the complexity of information, this study uses the questionnaire to quantify the textual problem. This is easy to observe and analyze and is conducive to scientific conclusions.

In this paper, the construction of interactive training mode which referred to the conceptual framework of

Corresponding author: Jiao Pengfei, 1149427022@qq.com This research was financially supported by Xi'an Shiyou University Foundation: Interactive cultivation model between master and graduate in the discipline of economics and management. doctoral tutor Zhou Qiao ling established the reference role and responsibility, ${ }^{[2]}$ Liu Min proposed the mentor role as "mentor", the results of an investigation of the relationship between students and instructors of colleges and universities in China ${ }^{[3]}$ and Zhou Wenhui, ${ }^{[4]}$ The questionnaire was designed from four dimensions.There are Training institutions and training system; teaching effectiveness; beneficial guidance; fusion guidance.

(1)Training institutions and training system refers to the education and training institutions and their systems for the purpose of academic education or adult continuing education.

(2)Teaching effectiveness refers to the sense of distance between instructor and graduate student in space, time, way of thinking and target mode, and the appropriate sense of distance can promote the cultivation of graduate students.

(3)The beneficial guidance refers to tutors and postgraduates of training objectives to reach a consensus on the knowledge acquisition guidance effect, guide the beneficial contribution to the study of students.

(4)Fusion guidance refers to the cognitive orientation of graduate students, thinking orientation and mentor orientation, experience orientation, to build a harmonious relationship between master and graduate.

The design of the interaction between the master and graduate training model is easy to decentralize and quantitative analysis. This survey was conducted at the Xi'an Shiyou University. The main ways of questionnaire have survey and interview survey, as a graduate student and teacher in the school.Through online two-dimensional code 164 questionnaires, 164 questionnaires were recovered, the recovery rate of $100 \%$ and 1 do not meet the requirements, the effective rate was $99.4 \%$.

\section{RESULTS}

First, the basic classification of the survey object is described that is the first part of the questionnaire. The survey results show that the proportion of grade:52\%, $20 \%$, $28 \%$.Graduate third grade most students in the internship who do not participate in the survey, so the main research object is Postgraduate first grade and Postgraduate sophomore. 
Secondly, compare the four dimensions of the interactive training mode, which is the most important factor that affects the ability of students to improve the students' preference, so do a single factor analysis of variance, shown in table I:

TABLE I. VARIANCE ANALYSIS OF SINGLE FACTOR

\begin{tabular}{|c|c|c|c|c|c|c|}
\hline \multirow{2}{*}{ (I) type } & \multirow{2}{*}{ (J) type } & \multirow{2}{*}{$\begin{array}{c}\text { Mean } \\
\text { difference(I-J) }\end{array}$} & \multirow{2}{*}{$\begin{array}{l}\text { Standard } \\
\text { error }\end{array}$} & \multirow{2}{*}{ Significance } & \multicolumn{2}{|c|}{$\begin{array}{c}95 \% \text { confidence } \\
\text { interval }\end{array}$} \\
\hline & & & & & $\begin{array}{c}\text { lower } \\
\text { limit }\end{array}$ & $\begin{array}{c}\text { Upper } \\
\text { limit }\end{array}$ \\
\hline \multirow{3}{*}{1} & 2 & $-.4218^{*}$ & .0946 & .000 & -.608 & -.236 \\
\hline & 3 & $-.2753 *$ & .0946 & .004 & -.461 & -.089 \\
\hline & 4 & $-.7746^{*}$ & .0946 & .000 & -.960 & -.589 \\
\hline \multirow{3}{*}{2} & 1 & $.4218^{*}$ & .0946 & .000 & .236 & .608 \\
\hline & 3 & .1465 & .0946 & .122 & -.039 & .332 \\
\hline & 4 & $-.3528 *$ & .0946 & .000 & -.539 & -.167 \\
\hline \multirow{3}{*}{3} & 1 & $.2753 *$ & .0946 & .004 & .089 & .461 \\
\hline & 2 & -.1465 & .0946 & .122 & -.332 & .039 \\
\hline & 4 & $-.4993 *$ & .0946 & .000 & -.685 & -.313 \\
\hline \multirow{3}{*}{4} & 1 & $.7746^{*}$ & .0946 & .000 & .589 & .960 \\
\hline & 2 & $.3528 *$ & .0946 & .000 & .167 & .539 \\
\hline & 3 & $.4993 *$ & .0946 & .000 & .313 & .685 \\
\hline \multicolumn{7}{|c|}{ *.The mean difference was significant at the 0.05 level } \\
\hline
\end{tabular}

Table type representative types, including Type 1 on behalf of the training institutions and training system, type 2 on behalf of the effectiveness of learning guidance, type of learning on behalf of the benefits of the type, type 4 represents the fusion of learning guidance.

After analysis, the data in a table can be found, the students of the four types of states have a secondary, type 4 is better than the other three types, the type 2 is better than the type 3 , but not significant, so the type 2 and type 3 the difference is not obvious. It is to say that the students in type 2 and type 3 state is almost identical to the 1 types of students, poor state, so we need to improve the type 1 which is the school for postgraduate training institutions and training system. This includes the hardware and software environment of scientific research, professional courses, mentor type 2 and type and so on. 3 should be maintained, And continue to strengthen, type 4 mainly describes the communication between teachers and students, the students should pay more attention to learn and mentor.

In addition to the four types analyzed above, the differences in the subjects themselves should be considered. Graduate students from the focus of learning into different academic graduate students and professional graduate students, so the need to graduate and professional academic graduate students by independent samples $\mathrm{T}$ test, two sample comparison, this method is more accurate. Compared two classes of students differences in various dimensions of the analysis should be strengthened and reserved. Results two independent samples T test. shown in table II :

The Data from table: For the system 1, the F value is 0.956 , the probability of the concomitant is more than the significance level of 0.05 , and can't reject the hypothesis of equal variance. It can be concluded that there is no significant difference between the academic and professional graduate students in the system 1.Then look at the $T$ test results of variance equal, concomitant probability $\mathrm{T}$ statistics is 0.023 lower than the significance level of 0.05 , to reject the null hypothesis $\mathrm{T}$ test. It is to say that academic research and professional students have significant differences in the 1 aspects of the system, so this should be further adjusted. In addition from the academic status sample mean difference the $95 \%$ confidence interval, the interval does not cross 0 , can also explain the two types of students have significant differences in the 1 aspects of the system.

For system 2, F-measure was 1.451 , with a probability of 0.230 , more than 0.05 significant level, cannot reject the assumption of equal variances, that there was no significant difference between the academic research and professional students in the system of 2 variance; and then look at the test results of variance are equal, accompanied by $\mathrm{T}$ statistics is 0.885 greater than the probability level was 0.05 , not to reject the null hypothesis $\mathrm{T}$ test. That is to say, academic research and professional students in the 2 aspects of the system does not exist significant differences, the two types of students are the same in system 2 state. Also from the sample mean difference and $95 \%$ confidence interval, interval there are 0 across, it can be explained that there are no significant differences between the two types of students in the system of the 2 aspects.

For system 3, F-measure was 3.109, with a probability of 0.080 , more than 0.05 significant level, cannot reject the assumption of equal variances, can think of academic and professional students in the system had no significant difference between the 3 Variance; and then look at the $\mathrm{T}$ test results of variance are equal, accompanied by $\mathrm{T}$ statistics is 0.954 greater than the probability level was 0.05 , not to reject the null hypothesis $\mathrm{T}$ test. That is to say, academic research and professional students in the 3 aspects of the system does not exist significant differences, the two types of students are the same in system 2 state. Also from the sample mean difference and $95 \%$ confidence interval, interval There are 0 across, it can be explained that there are no significant differences between the two types of students in the system of the 3 aspects.

For system 4, F-measure was 0.447 , with a probability of 0.505 , more than 0.05 significant level, cannot reject the assumption of equal variances, can think of academic and professional students in the system had no significant difference between the 4 Variance; and then look at the $\mathrm{T}$ test results of variance are equal, accompanied by $\mathrm{T}$ statistics is 0.336 greater than the probability level was 0.05 , not to reject the null hypothesis $\mathrm{T}$ test. That is to say, academic research and professional students in the 4 aspects of the system does not exist significant differences, the two types of students in the state system in 4 is the same. In addition from the sample mean difference and $95 \%$ confidence interval, there are 0 across, it can be explained that there are no significant differences between the two types of students in the system of the 4 aspects. 
TABLE II.

INDEPENDENT SAMPLE TEST

\begin{tabular}{|c|c|c|c|c|c|c|}
\hline \multirow{2}{*}{ (I)type } & \multirow{2}{*}{ (J) type } & \multirow{2}{*}{ Mean difference(I-J) } & \multirow{2}{*}{ Standard error } & \multirow{2}{*}{ Significance } & \multicolumn{2}{|c|}{ 95\% confidence interval } \\
\hline & & & & & lower limit & Upper limit \\
\hline \multirow{3}{*}{1} & 2 & $-.4218^{*}$ & .0946 & .000 & -.608 & -.236 \\
\hline & 3 & $-.2753 *$ & .0946 & .004 & -.461 & -.089 \\
\hline & 4 & $-.7746^{*}$ & .0946 & .000 & -.960 & -.589 \\
\hline \multirow{3}{*}{2} & 1 & $.4218^{*}$ & .0946 & .000 & .236 & .608 \\
\hline & 3 & .1465 & .0946 & .122 & -.039 & .332 \\
\hline & 4 & $-.3528 *$ & .0946 & .000 & -.539 & -.167 \\
\hline \multirow{3}{*}{3} & 1 & $.2753 *$ & .0946 & .004 & .089 & .461 \\
\hline & 2 & -.1465 & .0946 & .122 & -.332 & .039 \\
\hline & 4 & $-.4993 *$ & .0946 & .000 & -.685 & -.313 \\
\hline \multirow{3}{*}{4} & 1 & $.7746^{*}$ & .0946 & .000 & .589 & .960 \\
\hline & 2 & $.3528 *$ & .0946 & .000 & .167 & .539 \\
\hline & 3 & $.4993 *$ & .0946 & .000 & .313 & .685 \\
\hline
\end{tabular}

The teacher's emphasis on each aspect is also different, the type of the content and the table of the same, there is no longer repeat. Table three the focus of the study of the teacher to do the analysis.

The data in table three the following conclusions can be drawn. The difference between the average score of type 2 and the other three types is greater than zero, and the significance is less than 0.05.Type 2 is significantly better than the other three types. The average score between type 1 , type 3 , and type 4 is different, but the significance is greater than 0.05 , so the difference between them can be ignored.

TABLE III. SAMPLE FACTOR VARIANCE ANALYSIS

\begin{tabular}{|c|c|c|c|c|c|c|}
\hline \multirow{2}{*}{ (I)type } & \multirow{2}{*}{ (J) type } & \multirow{2}{*}{ Mean difference(I-J) } & \multirow{2}{*}{ Standard error } & \multirow{2}{*}{ Significance } & \multicolumn{2}{|c|}{ 95\% confidence interval } \\
\hline & & & & & lower limit & Upper limit \\
\hline \multirow{3}{*}{1} & 2 & $-.5038960727 *$ & .1336758548 & .000 & -.769725170 & -.238066976 \\
\hline & 3 & -.0060606091 & .1336758548 & .964 & -.271889706 & .259768488 \\
\hline & 4 & -.0181818182 & .1336758548 & .892 & -.284010915 & .247647279 \\
\hline \multirow{3}{*}{2} & 1 & $.5038960727 *$ & .1336758548 & .000 & .238066976 & .769725170 \\
\hline & 3 & $.4978354636^{*}$ & .1336758548 & .000 & .232006367 & .763664561 \\
\hline & 4 & $.4857142545^{*}$ & .1336758548 & .000 & .219885157 & .751543352 \\
\hline \multirow{3}{*}{3} & 1 & .0060606091 & .1336758548 & .964 & -.259768488 & .271889706 \\
\hline & 2 & $-.4978354636^{*}$ & .1336758548 & .000 & -.763664561 & -.232006367 \\
\hline & 4 & -.0121212091 & .1336758548 & .928 & -.277950306 & .253707888 \\
\hline \multirow{3}{*}{4} & 1 & .0181818182 & .1336758548 & .892 & -.247647279 & .284010915 \\
\hline & 2 & $-.4857142545^{*}$ & .1336758548 & .000 & -.751543352 & -.219885157 \\
\hline & 3 & .0121212091 & .1336758548 & .928 & -.253707888 & .277950306 \\
\hline
\end{tabular}

\section{COUNTERMEASURES AND SUGGESTION}

From the three table analysis, this paper gives out the following conclusions and recommendations: Countermeasures and suggestions

(1)From the perspective of graduate students to analyze, first of all, the school's training institutions and training system need to improve from the school to the graduate students to prepare the research room to the dormitory and other facilities need to be improved. Then graduated students and mentor in their academic goals also need to communicate more. The relationship between the teacher and student is very good. Therefore, graduate students should always contact with the tutor, so that teachers can always know your information. So easy to build a harmonious relationship between teachers and students.

(2)From the teacher's point of view, first, it is extremely important to have a suitable distance between the time and the way of thinking and the target model. Second, students and mentors should increase the number of meetings to help teachers understand your cognitive direction and academic goals. Finally, the teacher also suggested that the school should improve the scientific research environment and academic atmosphere.

(3)Comments on graduate students: in the spare time, you should increase the amount of excellent paper reading and summed up the highlights of outstanding papers in order to write their own later. But also pay attention to show them, should not be in the scientific research activities timid, should actively participate. In this process, the instructor can also have a certain understanding of graduate students, to facilitate the construction of a harmonious relationship between graduate students and mentors.

(4)Advice to the mentor. In the course of the training of graduate students, the tutor must strengthen its job responsibilities and urge the graduate students to form a good habit of self-study. At the same time, they should guide the teacher's guidance.

\section{CONCLUSION}

The cultivation of graduate students can't be ignored. Unlike undergraduates, graduate students not only have learning tasks, but also have researching tasks. You usually 
need to complete a certain scientific research before graduation. In this one, the tutor is the graduate vane who guides the direction of development of students. Therefore, it is important to establish a harmonious relationship with the mentor. Good teacher-student relationship can't only promote the progress of research, but also for students in the future work, study and life will have a very good help. Often contact with the instructor and show the ability to be an important way to establish a good relationship between teachers and students. Graduate students should strengthen the ability to consciously study. Cultivate strong self-learning ability, which will have a very important role in future work.

\section{REFERENCES}

[1] graduate student and teacher relationship type analysis of college advisor [J]., 2011(12): 1-3. (In Chinese)

[2] Zhou Qiaoling. The role and concept framework for the construction of [J]. degree and postgraduate education responsibility doctoral tutors, 2008 (9): 26-29.(In Chinese)

[3] Liu Min, Junxiang Xu, Guohong Wang. The development of education in the occupation role of tutor the graduate [J]. Journal of Beijing University of Technology, 2009 (1): 77-80.(In Chinese)

[4] Zhou Wenhui, Aixiu Zhang, Junqi Liu, et al. The present situation of our country university graduate student and teacher relationship survey [J]. academic degree and graduate education, 2010 (9): 7-14.(In Chinese) 